\title{
On application of emulsified probiotic preparation of Bacillus subtilis
}

\author{
Evgeny Skvortsov*, Rishat Mukhammadiev, Rinat Mukhammadiev and Lenar Valiullin \\ Federal Center of Toxicological, Radiation and Biological Safety - Russian Scientific Research Veterinary Institute, Kazan, 420075 , \\ Russia
}

\begin{abstract}
The use of a new form of the probiotic preparation of Bacillus subtilis consisting in emulsion of bacteria in palmitic acid has been studied. When evaluating the effectiveness of probiotics, it was assumed that the content of bacterial DNA in the feces is proportional to their content in the intestine. Analysis of the number of bacterial DNA was carried out by real-time PCR. The results showed a positive effect from the use of emulsified bacteria. It was observed in an increase in the amount of B. subtilis in the intestine and, as a consequence, their DNA in the feces of rats.
\end{abstract}

\section{Introduction}

Livestock farming is one of the fastest growing sectors of agriculture, its share is about $45 \%$ of the global value of agricultural production.

The use of probiotics in animal breeding is becoming an integral part of this process, since $80 \%$ of animal immunity depends on the work of the intestines, the synthesis of vitamins and amino acids, the digestion of feed and the absorption of all necessary substances, minerals and metabolic products.

Meanwhile, maintaining a large livestock farm often forces the use of antibiotics in animal feed. This can cause antibiotic resistance in microbial populations associated with human and animal diseases, such as salmonellosis and others.

Probiotics are becoming increasingly popular as one of the alternatives to using antibiotics to prevent and control the intestinal pathogens of animals. Although it has now been determined that probiotics are useful, the results vary widely and information on their mode of action and impact on the gastrointestinal microbial ecology is limited [1]. Today, the functions of microbes found in the gastrointestinal tract (GIT) have not been sufficiently studied. Probiotics help prevent and control gastrointestinal pathogens and through various mechanisms improve farm animal productivity. Even closely related strains may vary in mode of action $[2,3]$. Maintaining intestinal health in animals, especially in the context of abandoning antibiotics through diet manipulation, is important to increase the productivity of farm animals [4].

One of the main determinants of a healthy digestive tract is a composition of microbial population. Probiotics can change the dynamics of the microbial population in the digestive tract, creating a more favorable microbial population due to a shift in the balance of beneficial and harmful microbes [5-7]. The normal microflora of gastrointestinal tract ensures the optimal functioning of all body systems, including the immune system, and high productivity [8]. The decrease in the number of pathogenic microorganisms in the gastrointestinal tract may be associated with the production of antimicrobial substances, such as bacteriocins [9] and the adhesion of probiotic microbes to intestinal epithelium, which competitively displaces pathogenic microorganisms. The most common transformation of the gastrointestinal microflora by probiotics is an increase populations of lactobacilli and bifidobacteria [9-20], and a decrease in the populations of coliform bacteria, in particular Escherichia coli $[8,9,11,13-19,21]$ and Clostridium [9, 14-16]. This picture of gastrointestinal microflora changes occurs with lactic acid bacteria (LAB) $[11,16,18]$ and Clostridium butyricum [12, 22], used as probiotics. Bifidobacteria and lactic acid bacteria, producing lactic and acetic acid, which as well as bacteriocins, are antagonists to pathogenic and opportunistic microorganisms: shigella, enteropathogenic Escherichia coli, salmonella, staphylococci and others [23]. They have the greatest inhibitory effect on Staphylococcus aureus and Shigella sonnei, which are most often the cause food poisoning by dairy products. Partial or complete elimination of bifidobacteria and lactic acid bacteria leads to disturbances in the digestion, absorption and intestinal microflora colonization of the intestine. In addition to the antagonistic effect, they also show antioxidant activity [24, 25].

The application of spore probiotics prevents the development of dysbacteriosis, stimulates cellular and humoral factors of immunity, increases the nonspecific resistance of the body, stimulates regeneration processes in the body, and normalizes metabolism [26]. Acid and bile resistances are important characteristics of probiotic strains [27]. Spore-forming bacteria Bacillus sp. are

* Corresponding author: eskvortsov@ rambler.ru 
widely used as probiotics in the treatment of diseases of the gastrointestinal tract [28-31], as these microorganisms are not pathogenic both for humans and for animals [32].

The authors of this article are conducting studies of effective probiotic preparations for animal husbandry. Laboratory rats are a generally accepted model for the study of probiotic preparations for their further use in industrial animal husbandry.

To solve this problem, fast and accurate methods were necessary for the quantitative determination of the studied bacteria in the intestine during the use of these probiotic preparations.

It should be noted that the quality of standard microbiological methods, according to our studies, is very low. A large number of bifidobacteria die in the process of sampling and analysis. The test results depend strongly on the minimal differences in the procedures of microbiological seeding operations, which cannot be avoided. The errors of such methods exceed the effect of probiotic preparations use.

Bacteria often die under conditions that are not optimal for them, in particular in aggressive conditions of the stomach. As a result, the use of probiotic preparations looks like the "black box" principle, where it is not clear what happens to bacteria taken orally.

In the intestine, bacteria grow (increase in number) and die off (decrease in number), then are removed with feces in both live and dead forms. The content of bacteria in the feces is proportional to their content in the intestine. Each genus of bacteria has its own unique genes. We can get data about the effectiveness of probiotics, by making a quantitative genetic analysis of fecal dry matter content for corresponding specific bacteria genes, studying its dynamics. It is possible to carry out such analysis by real-time PCR (quantitative PCR). That method allows determining after amplification the amount of a specific gene (DNA).

The digestion of monogastric animals is characterized by the fact that fats do not undergo chemical changes in the oral cavity due to the absence of lipolytic enzymes, and the lipase content in the stomach is extremely low. In addition, the $\mathrm{pH}$ of gastric juice (1.0-1.5) is not optimal for gastric lipase (5.5-7.5). There are no fat emulsifiers in the stomach, and gastric lipase can only break down pre-emulsified fats. Lipids are digested in the thin intestine, where there is a slightly alkaline environment that is optimal for lipase activity. Water-soluble glycerin, fatty acids with less than 10 carbon atoms absorb diffusely into the portal vein. Fatty acids with more than 10 carbon atoms form a micelle, the outer shell that contains bile salts. Bile salt micelles act as transport intermediaries for transferring free fatty acids to the brush border of the intestinal epithelium, otherwise free fatty acids will be insoluble. Here, free fatty acids are absorbed into the blood, and bile salts are released back into the chyme to be reused for the transfer process.

Considering these features of the digestion of fats and fatty acids, it was decided to study the possibility of transporting probiotic bacteria $B$. subtilis through the stomach into the intestine emulsified in palmitic fatty acid.

\section{Materials and Methods}

The experiments were carried out on 60 white outbred male rats.

We used a strain of bacilli Bacillus subtilis (strain JH 642). To obtain a probiotic preparation B. subtilis was cultured on L-broth, (\%): Difco peptone - 1.0; yeast extract $-0.5 ; \mathrm{NaCl}-0.5$. The culture fluid was diluted so that its optical density was $0.25-0.05$ units at $\lambda=590 \mathrm{~nm}$ and was used as an inoculum for inoculation of deep cultures. Cultural environments of deep cultures were seeded with $2 \%$ of the inoculum. The cultures were grown in $200 \mathrm{ml}$ flasks containing $50 \mathrm{ml}$ of medium for 24-72 hours on laboratory shakers with intensity $100 \mathrm{rpm}$ at temperature $37^{\circ} \mathrm{C}$ to a content $10^{7}$ cells $/ \mathrm{ml}$.

The preparation was obtained by emulsification of B. subtilis cells by mixing with palmitic acid based on the weight parts of $1: 10$. Thus, the preparation contained $10^{6}$ cells / gram of fat emulsion. One dose of the preporation was equal to $10^{6}$ cells of $B$. subtilis.

Experimental group No. 1 amounted of 20 outbred male rats and received feed barley with the addition of the drug in the form of a culture suspension, and after 1 day - palmitic acid. Experimental group No. 2 also amounted of 20 outbred rats and received feed barley with the equivalent amount of $B$. subtilis cells in the form of an emulsion in the same amount of palmitic acid. A control group of 20 rats received feed barley with the addition of palmitic acid, equal in number to the experimental groups, but without the addition of a probiotic preparation.

DNA was isolated from feces of rats using the DNASorb-B kit (Interlabservis, Russia). Using the data of the internet resource Genbank, Blast, DINAMelt and Vector NTI program, specific primers and fluorescent probes for B. subtilis gyr A (AY663697.1) gene were selected for Real time PCR. Amount of DNA Bifidobacterium sp. and Lactobacillus sp. were determined using the «Colonoflor» reagent kit (Alfalab, Russia). Amplifier used T-100 Real-Time PCR Detection System, Bio- Rad, USA.

Studies of the effect of probiotic preparations on rat blood hematological parameters included: hemoglobin content, the number of red blood cells, white blood cells and \% lymphocytes using a Mythic 18 hematology analyzer (C2 Diagnostics, France).

Studies of the effect of probiotic preparations on rat blood biochemical parameters included blood serum testing for: glucose, urea, total protein, alanine aminotransferase (AlAT), asparagine aminotransferase (AsAT) using a Stat fax 3300 biochemical analyzer (Awareness Technology, USA) and Olvex reagent kit (Olveks diagnosticum, Russia).

Blood was drawn from the tip of the tail. The first blood sampling was carried out immediately before the start of the experiment and then every week. If a probiotic preparation was introduced into the diet of rats, 
blood sampling was performed immediately before administration.

Mathematical apparatus Microsoft Excel program was used for statistical processing of the results.

\section{Results and Discussion}

In the feces of the control group of rats that did not receive the $B$. subtilis probiotic supplement, the amount of bacterial DNA of B. subtilis was stable at 1.5-1.8 $\mathrm{lg}$ DNA/gram for the duration of the experiment (Fig. 1).

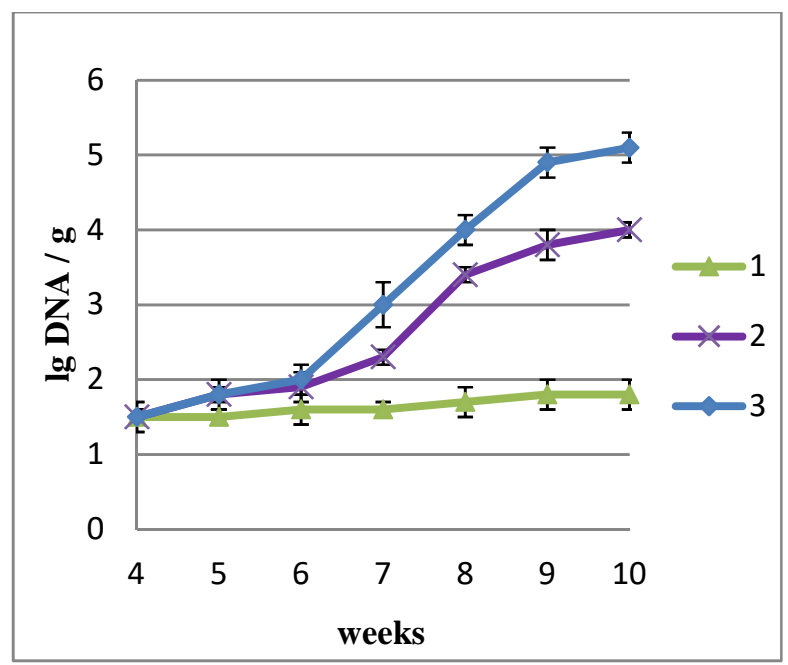

Fig. 1. The growth of $B$. subtilis biomass during the use of a probiotic preparation. (Row - 1 - control group of rats; row 2 - experimental group No. 1 ; row -3 - experimental group No. 2)

The control group and experimental group No. 1 received palmitic acid in amounts equal to experimental group No. 2, but without emulsified bacteria. The obtained numbers of the experimental group No. 1 were $1.5 \pm 0.1 \mathrm{lg} \mathrm{DNA} / \mathrm{g}$ for $B$. subtilis at the beginning of the experiment and increased to $4.0 \pm 0.2 \mathrm{lg} \mathrm{DNA} / \mathrm{g}$ at the end. When comparing the data of experimental group No. 1 and No. 2, it is seen that at the end of the experiment in both cases the content of B. subtilis in feces increased. However without the use of palmitic emulsion it increased to $4.0 \pm 0.2 \mathrm{lg} \mathrm{DNA} / \mathrm{g}$, and with one - up to $5.1 \pm 0.2 \mathrm{lg} \mathrm{DNA} / \mathrm{g}$. Palmitic acid protects the vegetative cells of $B$. subtilis from the aggressive conditions of the stomach and high concentrations of bile in the duodenum during digestion.

In addition, with increase in $B$. subtilis, decrease the number of Bifidobacterium sp. and Lactobacillus sp. in the feces of experimental group rats (Fig. 2, 3).

The hematological parameters of rat blood during the experiment are shown in Table 1. Studies have shown that the leukocyte number did not significantly change in all groups of the studied rats and was within the physiological norms in the range $(11-12) \times 10^{9} / 1$. The optimal number of white blood cells is demonstrated when there are no infections of bacterial or viral origin in organism. In particular, this means that there is no infectious effect of applied probiotic B. subtilis strain on rats. In addition, a stable level of leukocytes indicates the absence of allergens and diseases associated with the lymphoproliferative process, internal bleeding. \% of lymphocytes also usually grows due to infections. Studies have shown that $\%$ of lymphocytes did not significantly change in all groups of rats, it indicates the absence of infections. Hemoglobin and red blood cells increased slightly during the experiment in direction "Control - No. 1 - No. 2 groups", within $2 \%$, but were also within the normal range.

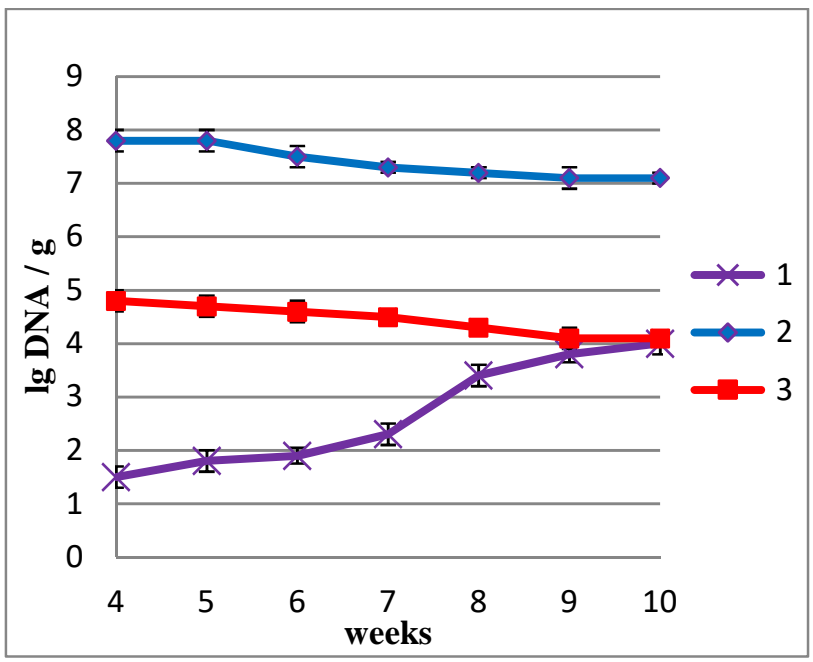

Fig. 2. Amount of DNA B. subtilis (row - 1), Bifidobacterium sp. (row - 2) and Lactobacillus sp. (row - 3) in the feces of experimental group rats No. 1 during experiment.

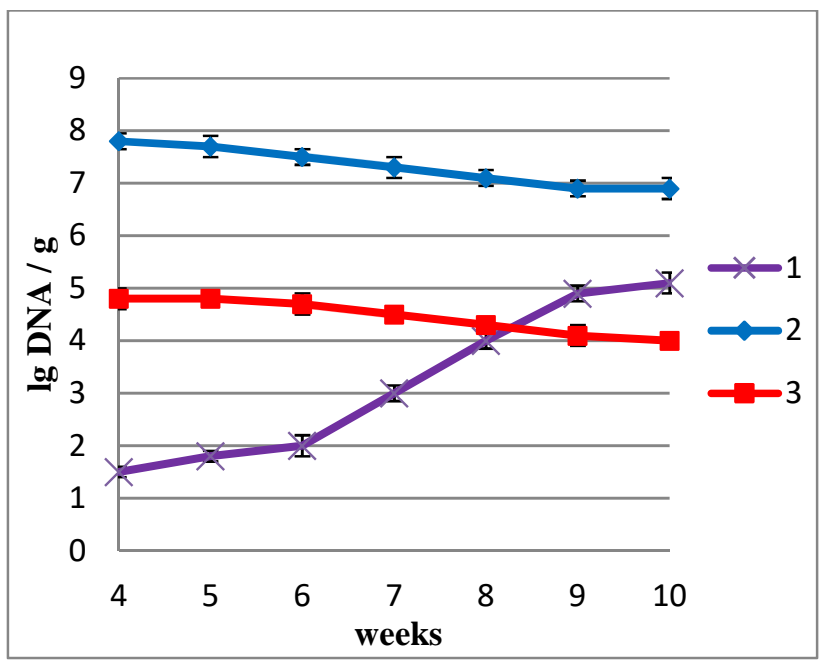

Fig. 3. Amount of DNA B. subtilis (row - 1), Bifidobacterium sp. (row - 2) and Lactobacillus sp. (row - 3) in the feces of experimental group rats No. 2 during experiment.

The rat blood biochemical parameters during the experiment are shown in Table 2. A high level of transaminases can indicate myocardial infarction, hepatitis, cirrhosis, metastatic carcinoma, liver diseases [33], muscular dystrophy, acute pancreatitis and other organ damage. An increases AlAT and AsAT indicates necrotic changes in the body, therefore it is widely used to quickly determine the severity of the disease. Normally, the activity of AlAT and AsAT in the blood is low. The results of the study show that the activity of AlAT and AsAT in intact rats and animals treated with 
the drug was comparable, indicating the absence of any toxic effect of the probiotic preparation.

Blood urea increased during the experiment in all rat groups, but in the experimental groups it grew faster. Moreover, in experimental group No. 2, the growth was faster than in the experimental group No. 1. At the end of the experiment, the experimental group No. 1 had a higher blood urea than the control group by $2.5 \%$, and the experimental group No. 2 by $5.7 \%$. Thus, there is a correlation between an increase in the content of $B$. subtilis in the intestine and urea in the blood of rats.

Table 1. Hematological and biochemical parameters of rat blood

\begin{tabular}{|c|c|c|c|c|}
\hline Age, weeks & Indicators blood & Control group & Experienced group № 1 & Experienced group № 2 \\
\hline \multirow[t]{9}{*}{5} & Red blood cells $10^{12} / 1$ & $7.37 \pm 0.33$ & $7.39 \pm 0.31$ & $7.41 \pm 0.37$ \\
\hline & Hemoglobin, g/l & $150.75 \pm 8.37$ & $151.05 \pm 8.31$ & $151.77 \pm 7.97$ \\
\hline & White blood cells, $10^{9} / 1$ & $11.53 \pm 0.83$ & $11.64 \pm 0.97$ & $11.76 \pm 0.72$ \\
\hline & Lymphocytes, \% & $67.351 \pm 3.01$ & $67.53 \pm 2.98$ & $66.94 \pm 3.76$ \\
\hline & Total protein, $\mathrm{g} / \mathrm{l}$ & $59.28 \pm 3.01$ & $60.47 \pm 3.73$ & $59.87 \pm 3.65$ \\
\hline & Glucose, $\mathrm{mM} / 1$ & $5.52 \pm 0.13$ & $5.54 \pm 0.12$ & $5.19 \pm 0.15$ \\
\hline & Urea, $\mathrm{mM} / \mathrm{l}$ & $5.15 \pm 0.19$ & $5.18 \pm 0.18$ & $5.20 \pm 0.15$ \\
\hline & $\mathrm{AlAT}^{*}, \mathrm{microM} / \mathrm{s} \times \mathrm{l}$ & $1.24 \pm 0.17$ & $1.58 \pm 0.12$ & $1.18 \pm 0.56$ \\
\hline & AsAT $^{* * *}$, microM/s $\times 1$ & $1.28 \pm 0.15$ & $0.58 \pm 0.14$ & $1.18 \pm 0.33$ \\
\hline \multirow[t]{9}{*}{6} & Red blood cells $10^{12} / 1$ & $7.39 \pm 0.30$ & $7.40 \pm 0.31$ & $7.43 \pm 0.33$ \\
\hline & Hemoglobin, g/l & $151.75 \pm 8.37$ & $152.05 \pm 8.31$ & $153.77 \pm 7.97$ \\
\hline & White blood cells, $10^{9} / 1$ & $11.85 \pm 0.77$ & $11.45 \pm 0.78$ & $11.66 \pm 0.71$ \\
\hline & Lymphocytes, \% & $68.30 \pm 3.17$ & $66.34 \pm 3.77$ & $65.32 \pm 2.97$ \\
\hline & Total protein, $\mathrm{g} / \mathrm{l}$ & $59.83 \pm 2.67$ & $59.37 \pm 3.18$ & $59.66 \pm 3.42$ \\
\hline & Glucose, $\mathrm{mM} / \mathrm{l}$ & $5.12 \pm 0.27$ & $5.22 \pm 0.28$ & $5.10 \pm 0.25$ \\
\hline & Urea, $\mathrm{mM} / \mathrm{l}$ & $5.17 \pm 0.20$ & $5.28 \pm 0.19$ & $5.31 \pm 0.18$ \\
\hline & $\mathrm{AlAT}^{*}, \mathrm{microM} / \mathrm{s} \times \mathrm{l}$ & $1.76 \pm 0.22$ & $1.53 \pm 0.07$ & $1.83 \pm 0.73$ \\
\hline & AsAT $^{* * *}$, microM/s $\times 1$ & $1.02 \pm 0.14$ & $0.86 \pm 0.20$ & $0.79 \pm 0.23$ \\
\hline \multirow[t]{9}{*}{7} & Red blood cells $10^{12} / 1$ & $7.41 \pm 0.34$ & $7.43 \pm 0.34$ & $7.45 \pm 0.42$ \\
\hline & Hemoglobin, g/l & $151.75 \pm 8.31$ & $152.55 \pm 7.91$ & $155.90 \pm 8.17$ \\
\hline & White blood cells, $10^{9} / 1$ & $11.77 \pm 0.83$ & $11.54 \pm 0.91$ & $11.92 \pm 0.83$ \\
\hline & Lymphocytes, \% & $68.73 \pm 3.79$ & $67.35 \pm 3.19$ & $66.28 \pm 3.09$ \\
\hline & Total protein, $\mathrm{g} / \mathrm{l}$ & $60.71 \pm 2.92$ & $60.75 \pm 3.04$ & $59.57 \pm 3.26$ \\
\hline & Glucose, $\mathrm{mM} / \mathrm{l}$ & $5.17 \pm 0.29$ & $5.76 \pm 0.27$ & $5.75 \pm 0.19$ \\
\hline & Urea, mM/l & $5.18 \pm 0.19$ & $5.21 \pm 0.17$ & $5.29 \pm 0.14$ \\
\hline & $\mathrm{AlAT}^{*}, \mathrm{microM} / \mathrm{s} \times \mathrm{l}$ & $1.45 \pm 0.05$ & $1.34 \pm 0.23$ & $1.98 \pm 0.17$ \\
\hline & AsAT $^{* *}$, microM/s $\times 1$ & $1.18 \pm 0.11$ & $1.08 \pm 0.19$ & $1.18 \pm 0.21$ \\
\hline \multirow[t]{9}{*}{8} & Red blood cells $10^{12} / 1$ & $7.41 \pm 0.43$ & $7.48 \pm 0.21$ & $7.49 \pm 0.27$ \\
\hline & Hemoglobin, g/l & $151.06 \pm 7.87$ & $152.94 \pm 7.12$ & $160.65 \pm 8.02$ \\
\hline & White blood cells, $10^{9} / 1$ & $11.51 \pm 0.79$ & $11.60 \pm 0.88$ & $11.60 \pm 0.71$ \\
\hline & Lymphocytes, \% & $67.78 \pm 3.07$ & $66.43 \pm 3.78$ & $66.29 \pm 3.16$ \\
\hline & Total protein, $\mathrm{g} / \mathrm{l}$ & $59.13 \pm 3.01$ & $60.39 \pm 3.18$ & $59.26 \pm 3.35$ \\
\hline & Glucose, $\mathrm{mM} / \mathrm{l}$ & $5.13 \pm 0.27$ & $5.21 \pm 0.21$ & $5.11 \pm 0.11$ \\
\hline & Urea, $\mathrm{mM} / 1$ & $5.19 \pm 0.19$ & $5.25 \pm 0.20$ & $5.37 \pm 0.12$ \\
\hline & AlAT $^{*}$, microM/s $\times 1$ & $1.16 \pm 0.82$ & $1.46 \pm 0.02$ & $1.14 \pm 0.54$ \\
\hline & AsAT $^{* * *}$, microM/s $\times 1$ & $0.99 \pm 0.17$ & $0.89 \pm 0.13$ & $1.01 \pm 0.19$ \\
\hline \multirow[t]{9}{*}{9} & Red blood cells $10^{12} / 1$ & $7.42 \pm 0.38$ & $7.49 \pm 0.34$ & $7.54 \pm 0.32$ \\
\hline & Hemoglobin, g/l & $151.44 \pm 7.88$ & $152.66 \pm 8.01$ & $152.98 \pm 8.99$ \\
\hline & White blood cells, $10^{9} / 1$ & $11.63 \pm 0.63$ & $11.65 \pm 0.76$ & $11.66 \pm 0.57$ \\
\hline & Lymphocytes, \% & $67.97 \pm 2.66$ & $66.94 \pm 3.98$ & $66.93 \pm 3.76$ \\
\hline & Total protein, $\mathrm{g} / \mathrm{l}$ & $59.99 \pm 3.11$ & $60.13 \pm 3.33$ & $60.06 \pm 3.87$ \\
\hline & Glucose, $\mathrm{mM} / \mathrm{l}$ & $5.31 \pm 0.32$ & $5.69 \pm 0.23$ & $5.56 \pm 0.21$ \\
\hline & Urea, $\mathrm{mM} / \mathrm{l}$ & $5.25 \pm 0.23$ & $5.38 \pm 0.23$ & $5.47 \pm 0.22$ \\
\hline & $\mathrm{AlAT}^{*}, \mathrm{microM} / \mathrm{s} \times \mathrm{l}$ & $1.18 \pm 0.09$ & $1.14 \pm 0.18$ & $1.07 \pm 0.16$ \\
\hline & AsAT $^{* *}$, microM/s $\times 1$ & $1.04 \pm 0.14$ & $1.18 \pm 0.13$ & $1.14 \pm 0.14$ \\
\hline \multirow[t]{9}{*}{10} & Red blood cells $10^{12} / 1$ & $7.42 \pm 0.23$ & $7.50 \pm 0.31$ & $7.54 \pm 0.39$ \\
\hline & Hemoglobin, g/l & $151.55 \pm 8.04$ & $152.65 \pm 8.23$ & $153.77 \pm 7.73$ \\
\hline & White blood cells, $10^{9} / 1$ & $11.62 \pm 0.72$ & $11.64 \pm 0.78$ & $11.65 \pm 0.67$ \\
\hline & Lymphocytes, \% & $67.34 \pm 3.01$ & $66.83 \pm 3.15$ & $66.72 \pm 3.09$ \\
\hline & Total protein, $\mathrm{g} / \mathrm{l}$ & $59.88 \pm 3.21$ & $60.11 \pm 3.32$ & $59.97 \pm 3.14$ \\
\hline & Glucose, $\mathrm{mM} / \mathrm{l}$ & $5.30 \pm 0.25$ & $5.54 \pm 0.22$ & $5.53 \pm 0.24$ \\
\hline & Urea, $\mathrm{mM} / 1$ & $5.25 \pm 0.15$ & $5.39 \pm 0.18$ & $5.55 \pm 0.16$ \\
\hline & $\mathrm{AlAT}^{*}, \mathrm{microM} / \mathrm{s} \times \mathrm{l}$ & $1.16 \pm 0.25$ & $1.11 \pm 0.32$ & $1.03 \pm 0.14$ \\
\hline & $\mathrm{AsAT}^{* *}, \mathrm{microM} / \mathrm{s} \times \mathrm{l}$ & $1.05 \pm 0.11$ & $1.17 \pm 0.21$ & $1.15 \pm 0.16$ \\
\hline
\end{tabular}


An increase in the concentration of urea in the blood may be a consequence of an increase in the intake of protein with food or increased protein catabolism. However, an increase in protein catabolism would had caused an increase in the activity of AlAT and AsAT, which was not found. This means that an increase in the concentration of urea in the blood is due to an increase in protein intake, which occurs as a result of improved digestion with an increase content of $B$. subtilis in the intestine.

Glucose and total blood protein were stable, in zone of normal physiological values and did not correlate with the content of $B$. subtilis in the intestine.

Thus, the introduction of $B$. subtilis bacterial preparations into the rat diet did not lead to the development of harmful effects and bad effects.

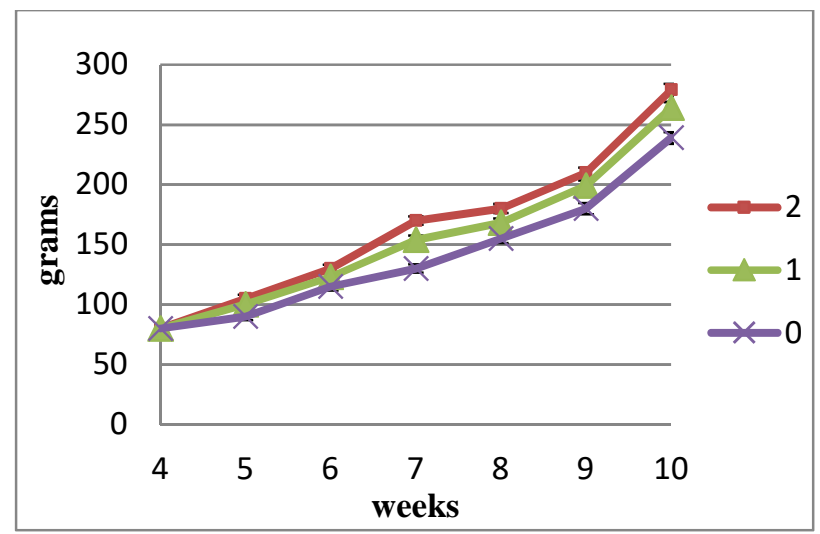

Fig. 4. Growth of rats mass during the use of probiotic preparation $B$. subtilis. (Row - 0 - control group of rats; row 1 - experimental group No. 1 ; row -2 - experimental group No. 2)

Figure 4 shows graphs of the increase in mass of rats in the control and experimental groups. The largest gain, during the experiment, was demonstrated by the experimental group No. 2, which took the emulsified preparation $B$. subtilis. The average rat weight at the end of the experiment was $279 \pm 5.0$ grams. The average weight of rats in experimental group No. 2 at the end of the experiment was $16.7 \%$ more in comparison with the control. A slightly smaller gain was demonstrated by experimental group No. 1, which took B. subtilis in the form of an aqueous suspension in culture fluid. The average rat weight at the end of the experiment was $264 \pm 4.9$ grams. The average weight of rats of experimental group No. 1 was $10.5 \%$ higher in comparison with the control at the end of the experiment.

Moreover, accelerated growth of rats was observed even with a slight decrease in the number of Bifidobacterium sp. and Lactobacillus sp. in the feces of experimental rat groups. Although, according to a number of sources [23-25], a decrease in bifidobacteria and lactic acid bacteria in the intestine leads to a deterioration in digestion processes and the development of pathogenic microflora. This means that B. subtilis is able to functionally replace these bacteria in the intestine without negative effects for the digestion of rats.

\section{Conclusion}

Studies have been conducted on the use of a new form of the probiotic preparation in the form of an emulsion of B. subtilis bacteria in palmitic acid. The results showed the presence of a positive effect of the use of emulsified bacteria on their survival during the passage of the gastrointestinal tract. It was reflected in an increase in their number in the intestines and, as a result, in the feces of rats. That is, emulsified bacteria are resistant to low $\mathrm{pH}$ of the stomach and high concentrations of bile in the duodenum. It means that emulsified B.subtilis preparations show signs of an effective probiotic for use in animal husbandry.

\section{References}

1. K. Ajuwon, J. of Appl. Poultry Res. 25, 277-283 (2015)

2. J. Fioramonti, Best Practice and Res. Clin. Gastroenterol. 17, 711-724 (2003)

3. M. Roselli, A. Finamore, M.S Britti et al., J. of Nutrit., 137, 2709-2716 (2007)

4. M. Choct, British Poultry Sci. 50, 9-15 (2009)

5. B. An, B. Cho, S. You, H. Paik et al., AsianAustralasian J. of Animal Sci. 21, 1027-1032 (2008)

6. K.C. Mountzouris, P. Tsirtsikos, E. Kalamara et al., Poultry Sci. 86, 309-317 (2007)

7. K.C. Mountzouris, C. Balaskas, I. Xanthakos, A. Tzivinikou, K. Fegeros, British Poultry Sci. 50, 467-478 (2009)

8. A.T. Hung, S.Y. Lin, T.Y. Yang, C.K. Chou et al., Animal Product. Sci. 52, 874-879 (2012)

9. Y. Shim, S. Ingale, J. Kim, K. Kim et al., British Poultry Sci. 53, 482-490 (2012)

10. W. Vahjen, A. Jadamus, O. Simon, Archives of Animal Nutrit. 56, 419-429 (2002)

11. K. Mountzouris, P. Tsitrsikos, I. Palamidi et al., Poultry Sci. 89, 58-67 (2010)

12. B. Zhang, X. Yang, Y. Guo, F. Long, Archives of Animal Nutrit. 65, 329-339 (2011)

13. V. Khaksar, A. Golian, H. Kermanshahi, African J. of Biotechnol. 11, 14716-14723 (2012)

14. C. Yang, G. Cao, P. Ferket, T. Liu et al., Poultry Sci. 91, 2121-2129 (2012)

15. A. Abdelqader, R. Irshaid, A.R. Al-fataftah, Tropical Animal Health and Product. 45, 1017-1024 (2013)

16. G.T. Cao, X.F. Zeng, A.G. Chen, L. Zhou et al., Poultry Sci. 92, 2949-2955 (2013)

17. N. Landy, A. Kavyani, Iranian J. of Appl. Animal Sci. 3, 703-708 (2013)

18. S. Mookiah, C.C. Sieo, K. Ramasamy, N. Abdullah, Y.W. Ho, J. of the Sci. of Food and Agricult. 94, 341-348 (2014)

19. H.S. Zhang, H.F. Wang, M. Shepherd, K. Wen et al., Gut Pathogens 6, 39-45 (2014) 
20. Z. Zhang, I. Kim, Poultry Sci. 93, 364-370 (2014)

21. H. Samli, S. Dezcan, F. Koc, M. Ozduven, A.A. Okur, N. Senkoylu, British Poultry Sci. 51, 564-568 (2010)

22. H. Yang, Y. Liu, S. Xu, Y. Li, Y. Xu, Acta Agricult. Zhejiangensis 24, 26-31 (2012)

23. I. A. Funk, A. N. Irkitova, Acta Biolog. Sibir. 2(4), 67-79 (2016)

24. E. I. Kvasnikov, O. A. Nesterenko, Lactic acid bacteria and ways to use them (Nauka, Moscow, 1975)

25. A. M. Amerkhanova, Public Health and Habitat 12, 35 (2012)

26. V. Lazar, L. Ditu, M., G.G. Pircalabioru et al., Frontiers in Immunol. 9, 1830 (2018)
27. M. Kim, D.G. Nam, S.B Kim, P. Im et al., Food Sci. \& Nutrit. 6(7), 1904-1913 (2018)

28. E. Isolauri, S. Salminen, A. Ouwehand, Best Pract. and Res. Clin. Gastroenterol. 18, 299-313 (2004)

29. S. Zhou, D. Song, X. Zhou, X. Mao et al., Fish Shellfish Immunol. 84, 1115-1124 (2019)

30. H.L. Jeon, S.J. Yang, S.H. Son et al., LWT 97, 94-99 (2018)

31. E.M. Quigley, Pharmacol. Res. 61, 213-218 (2010)

32. F.M.F. Elshaghabee, N. Rokana, R. D. Gulhane, C. Sharma, H. Panwar, Frontiers in Immunol. 8, 1490 (2017)

33. Sh. Sherlock, J. S. Dooley, Diseases of the Liver and Biliary System (Geotar-Med, Moscow, 2002) 